\title{
An Empirical Study on the Stakeholders Support on Rural Tourism and Sustainable Growth in Community Business -A Case Study of Karaikudi, Tamilnadu, India
}

Dr. Yavana Rani.S, Associate Professor, Acharya Bangalore B School, Bengaluru-560091, Karnataka, email: s.yavanarani@gmail.com

\begin{abstract}
This study tests the impact of stakeholders opinions about the impacts of tourism development and community participation and further to determine their willingness to support rural tourism and marketing strategies for sustainable growth of business using Structural Equation Modeling (SEM). The social exchange theory and stakeholders theory provide the theoretical background for this study. The study is descriptive in nature, and is based on both quantitative methodology to investigate the relationships between different constructs. The research study used survey questionnaires for quantitative data collection. The study area is a rural tourism spot Karaikudi, Sivaganga District in Tamilnadu, India. Convenience and quota sampling methods were adapted to collect quantitative data from different tourism stakeholders such as government authorities, businesses, residents, tourism faculty and students. The sample size is 320 . The data was then analyzed using the statistical package SPSS and model was tested using SEM.The research shows some statistical positive relationship between tourism development impacts people may experience, their desire for more participation in the decision-making process and tourism support. The result helps the rural tourism planners, governments and support organizations in other areas to better evaluate and understand the stakeholders' attitude and perceptions before implementing the project.
\end{abstract}

Keywords: Rural Tourism, Tourism Developmental Impacts, Community Participation, Tourism Support, Structural Equation Modeling (SEM).

\section{Introduction}

Identification of stakeholders' involvement in destination tourism planning and development, as well as the factors that might influence their level of involvement, is not only important for tourism destination planners, but also the host community's support for destination tourism development and competitive strategies. Tourism destinations need to plan their development strategies and actions to succeed internationally and gain a competitive advantage (Dowling, 1993; Riege \& Perry, 2000; Ritchie, 1993; Yuksel et al., 1999). Places that do not develop strategic planning of their destinations can suffer from economic, social, and environmental problems, as well as a decline in their competitiveness as a tourism destination (Dowling, 1993).

Rural tourism is a vital means of developing employment and income, can assist social and economic development of rural communities (Sharpley, 2001). The development of strong platform around the concept of rural tourism is definitely useful for a country like India, where almost $74 \%$ of the population sites in it 0.7 million villages (Ministry of Tourism, Government of India). Each village has its own distinctive performing arts and handicrafts, the customs and traditions, colorful festivals, cuisine as well as different cultures and historical heritage. The project is being implemented at 31 rural locations in 20 states with community participation through NGO or Panchayat Partners, District Collectors as focal points and specialized stakeholders. 
This study was approached from the tourism stakeholders' perspective about support for rural tourism destination competitiveness. Their perceptions, attitudes and behaviors in terms of tourism were assessed in this study. The model was tested using Structural Equation Modeling(SEM).

\section{Literature Review}

\section{Rural Tourism}

Negrusa et al., (2007) defines rural tourism as that form of tourism offered by people from rural areas, with accommodation on small-scale and with the implication of important components of their rural activities and customs of life. According to Roy A. Cook et al., (2007), tourism should be blended with the environment and the local culture of an area. Tourism should evolve from the area's natural and historical/cultural attractions. According to Garcia Ramon et al. (1995), tourism would be the 'saver' to improve the quality of life in the countryside and slow down the rural migration especially in less developed regions. Tourism would generate additional income for farm and rural families and create new jobs, lead to the stabilization of the rural economy, provide support to existing business and services, and contribute to creating new ones.

\section{Theoretical Background of Tourism Theories}

\section{The Social Exchange Theory}

The social exchange theory explains how people react to and support tourism development (Ap, 1992; Jurowski et al., 1997; Perdue et al., 1990; Yoon et al., 1999, 2000). Most of the studies have focused on how residents assess the benefits and costs of tourism development and have explained residents' support for future tourism development in particular region based on their evaluations of the benefits and costs of tourism (e.g. Jurowski et al., 1997; Yoon et al., 2000). Social exchange theory can be applied to residents' attitudes on the basis that residents seek various benefits in exchange for what they are able to offer to different tourism agencies, such as resources provided to tourism developers, tour operators, and tourists; support for tourism development; and being tolerable towards the negative impacts created by tourism(Teye et al. 2002).

\section{Stakeholder Theory}

Loannides (2001) applied a stakeholder framework concept to analyze varying stakeholder attitudes toward tourism and sustainable development at different stages of destination development. Stakeholder identification and involvement has been recognized as a key step toward achieving partnerships and collaboration within tourism in the studies of both Jamal and Getz (2000) and Bramwell (1999). The application of Stakeholder theory to tourism so far has been mostly superficial, with the exception of Hary and Beeton(2001) who applied Stakeholder theory to identify stakeholder groups and understand their perceptions of sustainable tourism.

\section{Research Methodolagy}

The stakeholders' perceptions, opinions, and demographic attributes were collected from both secondary and primary sources to resolve the research problem. The study is explanatory and descriptive in nature, and is based on both quantitative and qualitative analysis to investigate the relationships between tourism development impact factors (economic, socio-cultural, political, environmental), community participation (stakeholders' perceived power), and in turn the support of stakeholders for rural tourism competitive strategies.

\section{The Conceptual Framework and Hypothesis}

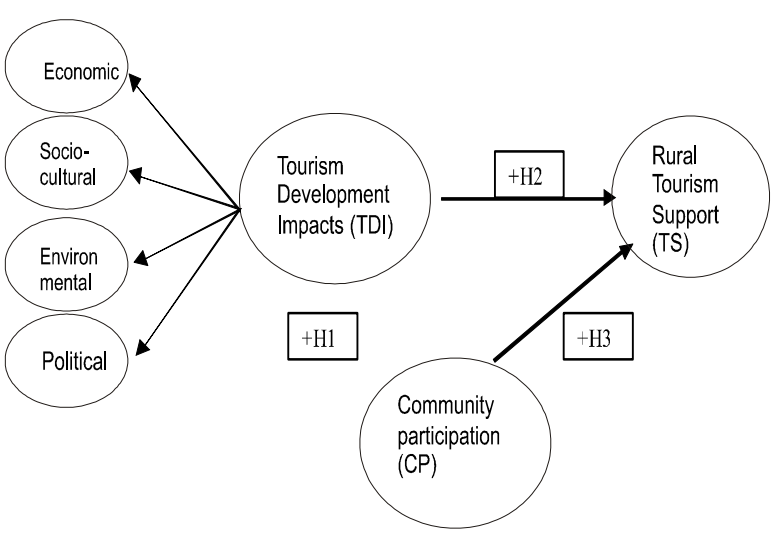

Source: Developed for this research with parts from Jurowski et al. (1997) and Yoon (2002) 
Figure 1: The initial conceptual framework for Rural Tourism Support

\section{Objectives of the Study}

To find the impact of tourism development and community participation on tourism support.

\section{Research Hypotheses}

$\mathrm{H} 1$ : There is a relationship between tourism development impacts (economic, social-cultural, environmental and political,) and the community participation.

$\mathrm{H} 2$ : There is a relationship between tourism development impacts (economic, social-cultural, environmental and political,) and the support for rural destination competitive strategies.

H3: There is a relationship between community participation and the support for rural destination competitive strategies.

\section{Research Design}

The study is explanatory and descriptive in nature. The quantitative analysis was used to investigate the relationships between tourism development impact factors (economic, socio-cultural, political, and environmental), community participation (stakeholders' perceived power) and in turn the support for rural tourism destination competitive strategies.

\section{Study Population}

The objective of this study was to investigate Karaikudi's tourism stakeholders' perceptions, attitudes, and behavior toward tourism and its development, the population of this study was tourism stakeholders. In particular, the target population includes members or groups that are related or are not related to tourism activities in the state Tamilnadu and in Karaikudi. Examples include state and local government officials, tourism, local tourism agencies, private businesses, residents, tourists and tourism faculties and students (researchers).

\section{Sample Size}

The research proposed to supply the instrument to 365 respondents in which only 320 respondents were willing to turn back with fully filled questionnaire. Therefore the response rate was $87 \%$.

\section{Sampling Technique}

Convenience and quota sampling methods were adapted methods from identified and independent sample frames to collect quantitative data from the respondents.

\section{Data Collection}

This study utilized a self-administered survey method and face-to-face interviews personally administered surveys with the selected tourism stakeholders in Karaikudi. However, prior to collecting the main data for the study, a pilot study was conducted to test the measurement.

\section{Measurement Scales and Research Instrument}

For this study, the survey was divided into six parts: a) the socio-demographic items b) tourism development impacts to measure the perceived impacts of tourism development, c) community participation, to measure the stakeholder' perceived power d) support for tourism e) overall community satisfaction, and f) tourist opinion. . The rating method, with a 5-point Likert scale (ranging from $1=$ strongly disagree to $5=$ strongly agree, $1=$ strongly oppose and $5=$ strongly support) was used for the measurement of perceived tourism development impacts, community participation (stakeholders' perceived power) and support for competitiveness strategies.

\section{Data Analysis}

The statistical analyses were done using SPSS 16 and the conceptual model was tested using (Analysis of Moment Structures) AMOS.

\section{STRUCTURAL MODEL FOR TOURISM SUPPORT}

The Structural model consists of three exogenous variables: Economic impacts, socio-cultural impacts, and political impacts (Tourism development impacts), and two endogenous variables community participation and Support for tourism destination (Figure 2).The exogenous variable Environmental impact has been eliminated in Confirmatory Factor Analysis (CFA), since it has no major impact on 
Tourism Development. The goodness-of-fit statistics for the structural model produced reasonable results, as shown in Table 2. The results of the structural equation modeling indicate an adequate model fit to the data.

In summary, the examinations of the absolute fit statistics indices suggested that the hypothesized model represented a mediocre fitting model to the data. The result of AGFI for this study is close to 1.00 and it is within the acceptable level of model fit. The values of CFI is 0.90 , suggesting that this values are sufficient to support a well fitting model.

Table 2:Model Fit Indices - Structural Model

\begin{tabular}{|c|c|c|}
\hline Model Fit indices & \begin{tabular}{|l} 
Structural \\
Model
\end{tabular} & Standardized Values \\
\hline $\begin{array}{l}\text { Absolute Fit } \\
\text { Measures } \\
\text { Chi-square of } \\
\text { estimate model } \\
\text { d.f } \\
\text { (X } 2 \text { /df) } \\
\text { Probability }\end{array}$ & $\begin{array}{l}661.717 \\
206 \\
3.212 \\
0.049\end{array}$ & $\begin{array}{l}<3 \text { (Byrne 1990) } \\
p<.05 \text { (Joreskog \& } \\
\text { Sorbom, 1996) }\end{array}$ \\
\hline $\begin{array}{l}\text { Goodness-of-fit } \\
\text { index (GFI) }\end{array}$ & 0.848 & $\begin{array}{l}\text { 0-1.Value close to } 1 \text { is } \\
\text { good fit } \\
\text { (Byrne, 1995; Hu \& } \\
\text { Bentler, 1995) }\end{array}$ \\
\hline $\begin{array}{l}\text { Root mean square } \\
\text { residual (RMR) }\end{array}$ & 0.087 & $<1$ (Hu \& Bentler, 1999) \\
\hline $\begin{array}{l}\text { Root mean square } \\
\text { error of } \\
\text { approximation } \\
\text { (RMSEA) }\end{array}$ & 0.08 & $\begin{array}{l}\text { 0.08 (mediocre fit) } \\
\text { (MacCallum, Browne \& } \\
\text { Sugawara, 1996) }\end{array}$ \\
\hline $\begin{array}{l}\text { Incremental Fit } \\
\text { Measures } \\
\text { Adjusted } \\
\text { goodness-of-fit } \\
\text { index (AGFI) } \\
\end{array}$ & 0.80 & $\begin{array}{l}\text { 0-1.Value close to } 1 \text { is } \\
\text { good fit } \\
\text { (Byrne, 1995; Hu \& } \\
\text { Bentler, 1995) }\end{array}$ \\
\hline $\begin{array}{l}\text { Parsimonious Fit } \\
\text { Measures } \\
\text { Comparative fit } \\
\text { index (CFI) }\end{array}$ & 0.90 & $\begin{array}{l}\text { 0-1.Value close to } 1 \text { is } \\
\text { good fit } \\
\text { (Byrne, Hu \& Bentler, } \\
1995 \text { ) }\end{array}$ \\
\hline
\end{tabular}

Note: All t-value were significant at the level of 0.05 .

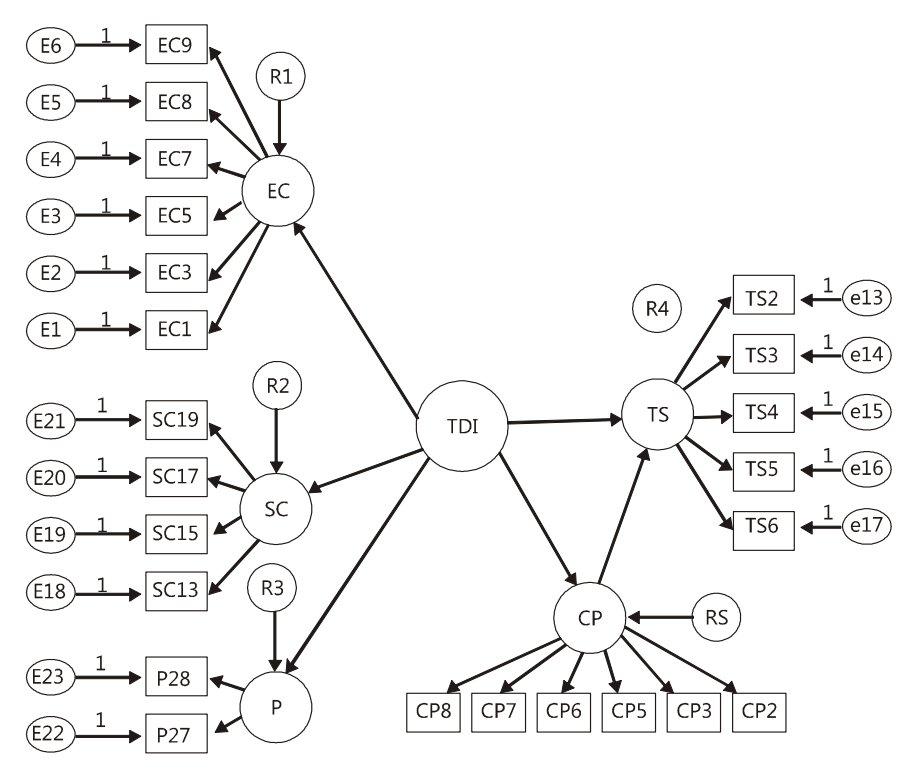

(E12) E11 E10 (E9) (E8)

Note:

\section{Economic Impact (EC)}

EC1-Tourism increases job opportunities for the local people

EC3-Wider promotion of handicraft items made in the village

EC5-Local labour, technology and resources being optimally utilized

EC7-Tourism creates more jobs for outsiders than for local people

EC8-Host community getting trained on different types of hospitality management, cuisine preparation, tourist handling

EC9-Collaboration with different business institutions for market tie-ups.

\section{Socio-Cultural Impact (SC)}

SC13-Mobilization of women artisans in the active participation in the tourism programme SC15-Effective skill building of the women community

SC17-Documentation of the crafts, arts and folk lore

SC19-Tourism encourages a variety of cultural activities by the local population 


\section{Political impact $(\mathbf{P})$}

P27-Tourism brings political benefits to society

P28-The community should have authority to suggest control and restrictions of tourism development in the country.

\section{Community Participation (CP)}

CP2-I would be willing to attend community meetings to discuss an important tourism issue CP3-The government usually consults us about tourism planning

CP5-Public involvement in planning and development of tourism

CP6-Active Participation of the local community and youth

CP7- willing to invest talent or time to make the community an even better place for visitors

CP2-I would be affected by whatever happens (positive or negative) in the community

\section{Tourism Support (TS)}

TS2- Development of cultural or historic-based attractions.

TS3- Development of supporting visitor services.

TS4- Development of small independent businesses.

TS5- Development of cultural and folk events.

TS6- Development of infrastructure for tourists.

Table 3: Summary of Hypotheses Testing

\begin{tabular}{|l|c|c|l|l|l|}
\hline \multicolumn{3}{|l|}{$\begin{array}{l}\text { Hypothesis Relation } \\
\text { ship estimate }\end{array}$} & $\begin{array}{l}\text { Beta } \\
\text { Estimate }\end{array}$ & $\begin{array}{l}\text { c.r } \\
\text { value }\end{array}$ & Results \\
\hline H1-CP & $<---$ & TDI & 0.897 & 9.218 & Supported \\
\hline H2-TS & $<---$ & TDI & 0.520 & 2.257 & Supported \\
\hline H3-TS & $<---$ & CP & 0.994 & 4.065 & Supported \\
\hline
\end{tabular}

In this proposed model, 3 hypotheses were proposed and tested by using structural equation modeling. From the outcome structural equation modeling the hypotheses were tested and the results are reported(Table:3). The final model has been tested and found to be a good fit the data and the possible model for this study.

\section{FINDINGS RECOMMENDATIONS}

The 'Tourism Development Impacts' constructs shows significant positive relationship with the construct of 'Tourism Support'. It was evident from the empirical data that the younger generation people and elderly people are less supportive for tourism than the middle aged people.It was hypothesized that tourism stakeholders who have a desire and interest in participating in tourism planning and benefits are more likely to support tourism development. In addition, the results showed a significantly strong positive relationship between the constructs 'community participation' and 'stakeholders' support for destination competitive strategies'.

Rural tourism can help in creating sustainable development in some of our villages in rural areas. Governments should recognize importance of rural tourism at priority and help in creating healthy competitive business environment. Government should try to generate data for decision-making bodies investing for developing the human resources, create adequate facilities and suitable infrastructure like accommodation, roads, airport facilities, rail facilities, local transport, communication links and other essential amenities become essential for development of rural tourism.

\section{REFERENCES}

1. Ap, J. (1992), "Residents' perceptions on tourism impacts", Annals of Tourism Research, 19 (4), 665-690.

2. Bramwell, B., \& Sharman, A. (1999), "Collaboration in local tourism policy-making", Annals of Tourism Research, 26(2), 392-415

3. Dowling, R. K. (1993), "Tourism planning, people and the environment in Western Australia", Journal of Travel Research, 3(4), 52-58. 
4. Garcia-Ramon, M. D. et al. (1995), "Farm tourism, gender and the environment in Spain", Annals of Tourism Research, (22) 2, p. 267-282.

5. Hardy, A.L. \& Beeton, R.J.S. (2001), "Sustainable tourism or maintainable tourism: Managing resources for more than average outcomes", Journal of Sustainable Tourism, 9(3), 168-192.

6. Ioannides, D. (2001). Sustainable development and the shifting attitudes of tourism stakeholders: Toward a dynamic framework. In S. F. McCool \& R. N. Moisey (Eds.), Tourism, recreation and sustainability: Linking culture and the environment (pp.55-76). New York: CABI Publishing.

7. Jamal, T. B. \& Getz, D. (2000),"Community roundtables for tourism-related conflicts: The dialectics of consensus and process structures", Journal of SustainableTourism, 7 (3/4), 290-313.

8. Jurowski, C., Uysal, M., \& Williams, D. R. (1997), "A theoretical analysis of host community resident reactions to tourism", Journal of Travel Research, 36(2),3-11.

9. Negrusa, A. L., Cosma, S. A., \& Bota, M, (2007), "Romanian rural tourism development a case study: rural tourism in Maramures" International Journal of Business Research, July.25-38
10. Perdue, R. R., Long. P. T., \& Allen, L. (1987), "Rural resident tourism perceptions and attitudes", Annals of Tourism Research, 14, 420-429.

11. Riege, A. M., \& Perry, C. (2000), "National marketing strategies in international travel and tourism", European Journal of Marketing, 34(11/ 12), 1290-1304.

12. Ritchie, J. R. B. (1993), "Crafting a destination vision: Putting the concept of residentresponsive tourism into practice", Tourism Management, 14(5),379-389.

13. Roy A.Cook, laura J.Yale, Joseph J. Marqua. Tourism, The Business of Travel. Pearson education, Inc. 2007, Third edition.

14. Sharpley, R. \& Roberts, L. (2004), "Rural tourism10 years on", International Journal of Tourism Research, 6, 119-124.

15. Yoon, Y., Gursoy, D., \& Chen, J. (2000), "Validating a tourism development theory with structural equation modeling", Tourism Management, 22(4), 363-372.

16. Yuksel, F., Bramwell, B., \& Yuksel, A. (1999), "Stakeholder interviews and tourism planning at Pamukkale, Turkey", Tourism Management, 20(3), 351-360. 